\title{
"Activación" e "dixitalización" nas aulas de Matemáticas Financeiras: A revolución de construír o proceso de aprender
}

\author{
De Llano Paz, Fernando; Martínez Fernández, Paulino
}

Departamento de Empresa, Facultade de Economía e Empresa,Universidade da Coruña.

\section{RESUMO}

0 nivel de atención e de asimilación dos conceptos da materia Análise das Operacións Financeiras impartida na Facultade de Economía e Empresa da UDC non son satisfactorios. A proposta reside nun cambio metodolóxico a través da combinación da aula invertida, da aprendizaxe baseada en proxectos (ABPy) e 0 traballo cooperativo. Búscase unha maior asimilación da materia a través do desenvolvemento de habilidades metacognitivas derivadas das estratexias das metodoloxías activas propostas.

0 cuadrimestre dividirase en dúas partes: Nas primeiras catro semanas do curso o docente explica e propón exercicios sobre os conceptos básicos da materia (capital financeiro, tipos de xuro, leis de capitalización e desconto, concepto de renda e préstamo). Preténdese provocar a participación activa, motivada e crítica na aula a través do emprego de accións publicitarias (anuncios). Nas seguintes dez semanas procédese a crear cinco grupos cooperativos. Estes deben: (1) afondar nos conceptos teórico-prácticos da materia, (2) elaborar un mapa conceptual e exercicios dixitais, ademais de (3) crear un vídeo didáctico da materia. Cada grupo vai subindo os materias creados ao google classroom, o que permite 0 control de actividade. A avaliación establécese por competencias. ¿0 cambio? Radical, apaixoante e motivador.

PALABRAS CLAVE: Aula invertida, ABPy, Grupos cooperativos 


\section{CITA RECOMENDADA:}

De Llano Paz, F.; Martínez Fernández, P. (2019): "Activación" e "dixitalización" nas aulas de Matemáticas Financieiras: A revolución de construír o proceso de aprender. En De la Torre Fernández, E. (ed.) (2019). Contextos universitarios transformadores: construíndo espazos de aprendizaxe. III Xornadas de Innovación Docente. Cufie. Universidade da Coruña. A Coruña (pág. 189-198).

DOI capítulo: https://doi.org/10.17979/spudc.9788497497121.189

DOI libro: https://doi.org/10.17979/spudc.9788497497121

\section{ABSTRACT}

The level of attention and assimilation of the concepts of the subject "Financial Operations Analysis" taught at Faculty of Economics and Business (UDC) are not satisfactory. The proposal is based on a methodological change through the combination of the inverted classroom, project-based learning (ABPy) and cooperative groups. A greater assimilation of the subject is sought through the development of metacognitive skills derived from the strategies of the proposed active methodologies.

The semester will be divided in two parts: In the first four weeks of the course the teacher explains and proposes exercises on the basic concepts of the subject (financial capital, interest rates, laws of capitalization and discount, concept of income and loan). It is intended to provoke active motivated and critical participation in the classroom through the use of advertising actions (announcements). In the following ten weeks five cooperative groups are created. These should: (1) deepen in the theoretical and practical concepts of the subject, (2) elaborate a conceptual map and digital exercises, as well as (3) create a didactic video of the subject. Each group is raising the subjects created on google classroom, which allows the control of activity. The evaluation is established by competencies. The change? Radical, exciting and motivating...

KEY WORDS: Inverted classroom; ABPy; Cooperative groups. 


\section{INTRODUCCIÓN}

0 nivel de atención e de asimilación dos conceptos da materia Análise das Operacións Financeiras impartida na Facultade de Economía e Empresa da UDC non son satisfactorios. Aínda que a asistencia do alumnado ás aulas é regular, os docentes constatan que a aprendizaxe da materia en moitos casos é tan só mecánica (aprender procesos de cálculo), deixando a un lado o nivel conceptual e de asimilación da materia no seu conxunto.

0 contexto de aplicación do Espazo Europeo de Educación Superior (en diante, EEES) anima a empregar outras metodoloxías distintas da lección maxistral que implican unha maior preparación previa e un maior grado de control e supervisión do proceso de ensinanzaaprendizaxe de cada alumno e que iría en liña cunha maior autonomía do estudante, maior aplicación práctica a traballar polo alumnado e un maior traballo en equipo. Segundo Zabalza (2011), o eixo fundamental para aplicar as metodoloxías máis acaídas no EEES debe estar baseado tanto na formación do profesorado como nunha boa organización curricular que inclúa 0 traballo por competencias e abandone 0 modelo curricular de disciplinas illadas e estancas.

Así mesmo, o EEES establece cambios na definición dos papeis a desenvolver tanto polos docentes como polo alumnado (Imaxe 1). A "activación" afecta deste xeito tanto a docentes, que deben pasar a ser guías de coñecementos e deben de achegar información regular ao alumnado sobre os seus avances (avaliación continua), como ao alumnado, que ve explicitada a súa responsabilidade no proceso de ensinanza-aprendizaxe. 


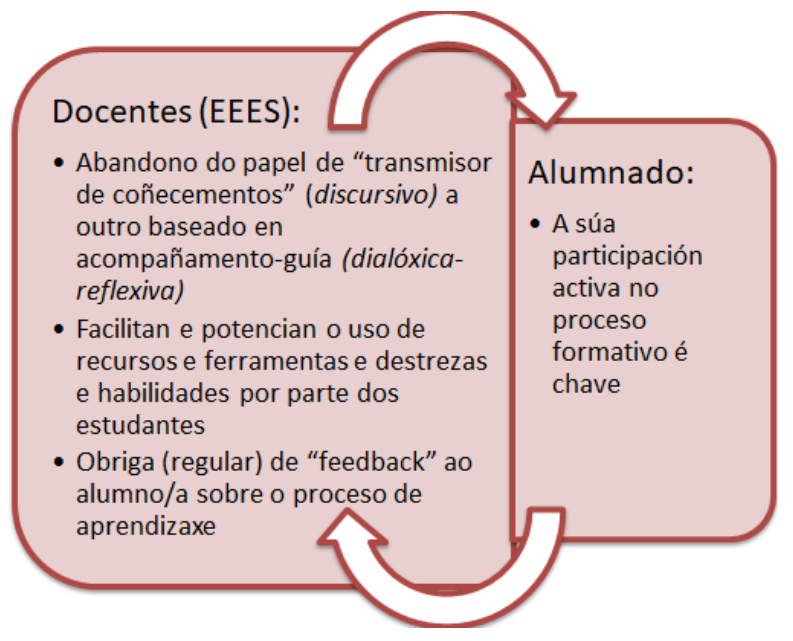

Imaxe 1. Cambios nos roles de docente e alumnado. Fonte: elaboración propia a partir de Cano (2009) e Fernández e De-Llano (2013)

Segundo o exposto anteriormente, proponse un cambio cara o uso de metodoloxías activas e dixitais na materia de matemáticas financeiras. A motivación desta proposta nace trala asistencia por parte dos autores ao curso do CUFIE de Manel Rives en xaneiro de 2018.

A proposta reside en combinar a aula invertida, a aprendizaxe baseada en proxectos (ABPy) e 0 traballo cooperativo. 0 resultado buscado é unha maior asimilación dos conceptos da materia a través do desenvolvemento de habilidades metacognitivas, que pivotará nas estratexias derivadas das metodoloxías activas propostas.

A continuación, desenvolveranse os elementos máis relevantes desta proposta didáctica. Así no punto 2 describirase os elementos máis relevantes sobre a experiencia, no punto 3 exporanse os resultados e no punto 4 proporanse as conclusións.

\section{DESCRICIÓN DA EXPERIENCIA}

0 cambio metodolóxico cara ao uso de metodoloxías activas baséase no entendemento da aprendizaxe como un proceso construtivo e de carácter autodirixido. Deste xeito estas 
metodoloxías activas dinamizan o uso de habilidades por parte do alumnado que van permitir traballar en equipo, argumentar e reflexionar sobre 0 aprendido.

A proposta de "activación" e "dixitalización" parte dun primeiro elemento, como é a sinatura do "contrato de aprendizaxe" no momento inicial. A fase de "activación" pódese contextualizar dentro dun proceso propositivo-provocativo e a fase de "dixitalización" incluiría un proceso formativo-creativo (Imaxes 2 e 3 ).

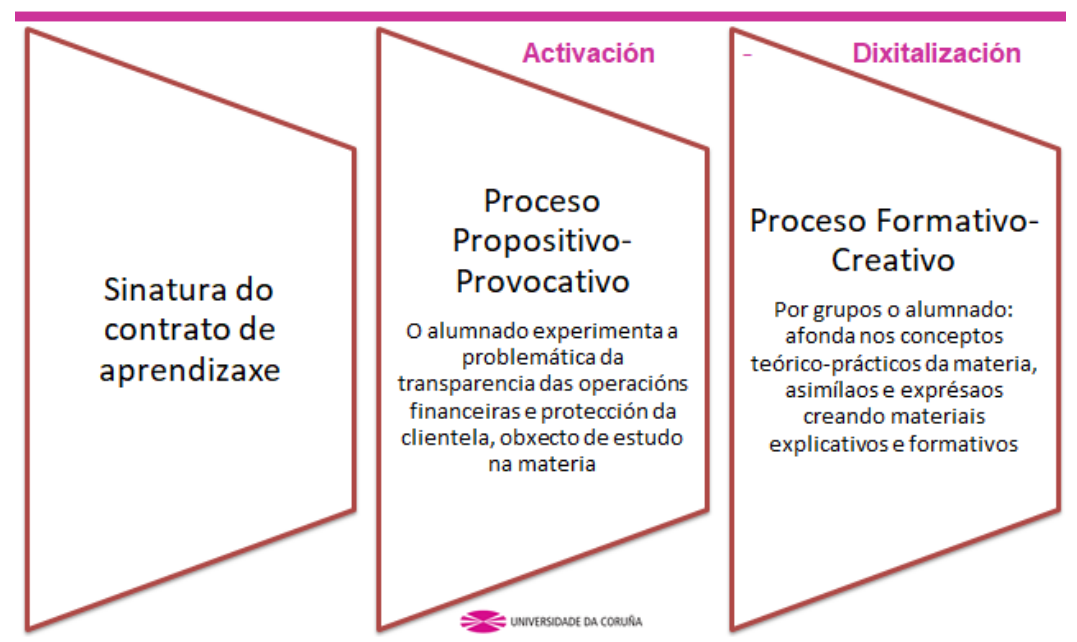

Imaxe 2. Fases da proposta. Fonte: elaboración propia.

\section{1.- SINATURA DO CONTRATO DE APRENDIZAXE}

0 curso iníciase coa sinatura do "contrato de aprendizaxe" onde cada alumno comprométese a asistir a un mínimo do 90\% das horas lectivas, de xeito activo, e a dedicar un mínimo de 3 horas á semana á materia. 0 contrato revísase na aula cada dúas semanas. Este "contrato de aprendizaxe" ou learning contract ten unha dobre función (Franquet et al., 2006; Miguel Díaz, 2006): trátase dunha ferramenta coa que traballar a responsabilidade e a motivación do alumnado en relación coa aprendizaxe activa, ademais de facilitar o proceso de avaliación continua, xa que neste contrato establécense os obxectivos da aprendizaxe, a metodoloxía a empregar o sistema de avaliación e o propio compromiso do alumnado. Entre as características deste contrato estarían as seguintes: defínese unha duración concreta, trátase 
dun acordo formal, establécese unha relación de contraprestación polas dúas partes ademais dunha implicación dos asinantes do mesmo. 0 contrato permite a adaptación do proceso de aprendizaxe ás necesidades do alumnado, e despraza en certa medida as necesidades do propio docente (Franquet et al., 2006).

\section{2- FASE DE “ACTIVACIÓN"A TRAVÉS DUN PROCESO PROPOSITIVO-PROVOCATIVO:}

Tras a sinatura deste contrato na primeira sesión, ten lugar o desenvolvemento da Fase de "activación". Durante as primeiras catro semanas do curso (aproximadamente 12 horas lectivas presenciais) 0 docente explica e propón exercicios iniciáticos sobre os elementos básicos dos eixos temáticos da materia (capital financeiro, tipos de xuro, leis de capitalización e desconto, concepto de renda e préstamo). A idea é fomentar inicialmente dende a practicidade da materia, 0 interese polos conceptos que hai detrás. Ademais 0 contexto de proposta destes exercicios prácticos son diversas informacións publicitarias de entidades financeiras e de produtos financeiros que saen nos medios. Preténdese con isto provocar a participación activa, motivada e crítica na aula por parte do alumnado. A idea é analizar a información que se achega nestes anuncios e interpretala dende 0 punto de vista teóricopráctico da materia, para finalmente poder achegar algunha recomendación como "expertos financeiros" aos consumidores. 0 alumnado experimenta así parte da problemática da transparencia das operacións financeiras e protección da clientela, obxecto de estudo na materia. 


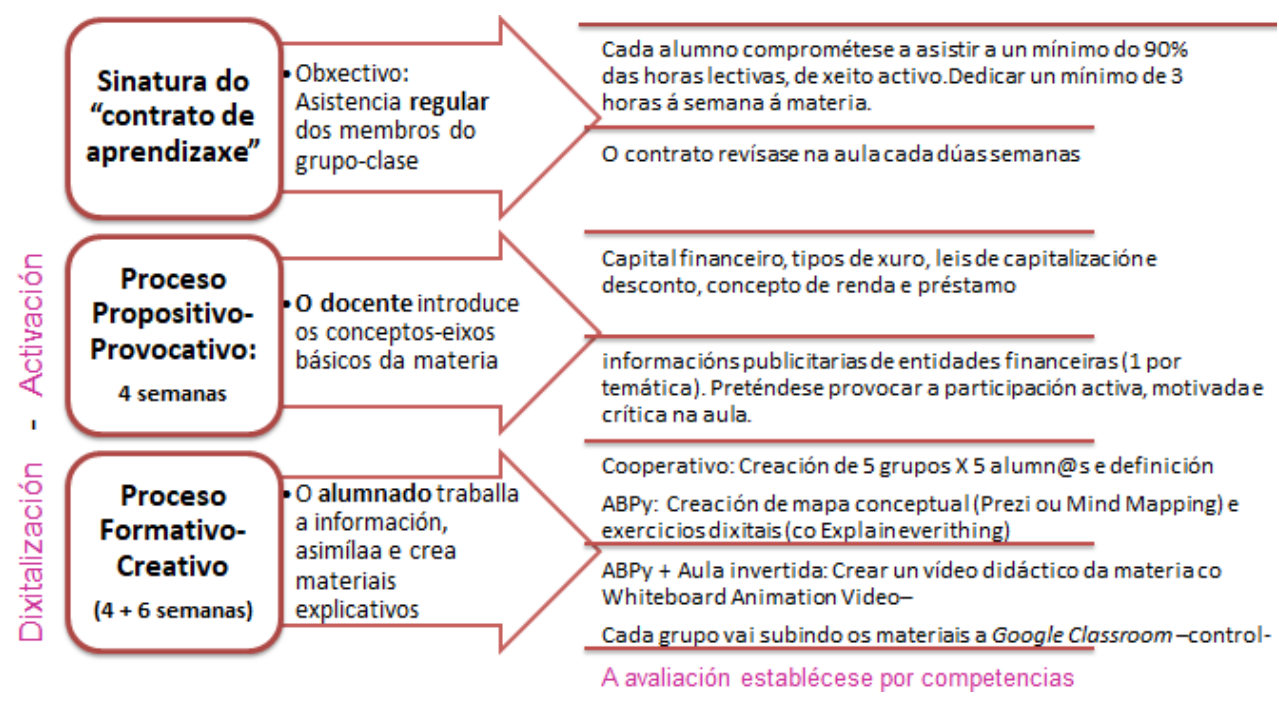

Imaxe 3. Descrición das fases da proposta. Fonte: elaboración propia.

\section{3.- FASE DE "DIXITALIZACIÓN" A TRAVÉS DUN PROCESO FORMATIVO-CREATIVO:}

Despois desta iniciación nos elementos básicos da materia, procédese a crear cinco grupos cooperativos de cinco alumnos cada un. Defínense os roles de aprendizaxe e a división das tarefas. Óptase por empregar a aprendizaxe cooperativa polas súas fortalezas (Gil, 2017): favorece a aprendizaxe independente e autodirixida, aumenta 0 grao de satisfacción dos estudantes coa experiencia de aprendizaxe, facilita a obtención dun maior rendemento académico en matemáticas, favorece 0 desenvolvemento da capacidade de observación e análise crítica das situacións propostas durante 0 proceso e potencia a implicación activa do alumnado no proceso de ensinanza-aprendizaxe.

Cada grupo cooperativo de clase debe:

- (1) afondar nos conceptos teórico-prácticos da materia,

- (2) elaborar un mapa conceptual -en Prezi ou Mind Mapping- e exercicios dixitais (co Explain everithing), 
- (3) crear un vídeo didáctico da materia -de 12 minutos máximo co Whiteboard Animation Video- no que se explique o paso do concepto de capital financeiro á resolución dun préstamo financeiro.

Para o proceso (1) de afondamento na materia dedícanse as seguintes catro semanas (en total van oito), nas que o docente entregará nas aulas presenciais fichas de desenvolvemento con exercicios teórico-prácticos coas que traballar nos grupos cooperativos.

Para o proceso de creación (2 e 3) -mapa, exercicios e vídeo- asígnanse as últimas seis semanas do curso. Deste xeito, unha vez o alumnado ten coñecemento dos conceptos básicos da materia, traballados nas primeiras oito semanas do curso, enténdese que están preparados para traballalos e asimilalos mediante a realización destas tres actividades. 0 contexto metodolóxico é 0 de aprendizaxe baseado en proxecto (ABPy). 0 traballo é amplo e divídese en tres elementos ou contidos -mapa, exercicios e vídeo-. 0 obxectivo final máis que a elaboración dos materiais, é a asimilación por parte do alumnado dos conceptos propostos na materia (Molina et al., 2007).

Ademais, a proposta trata de conectar así o aproveitamento presencial na clase co non presencial. A elaboración dos materiais esixe máis tempo que 0 que poidan, como grupo, dedicar nas clases lectivas. É por iso que se busca que traballen fóra da aula cun guión preestablecido que lles sirva como guía. A desculpa é xerar os materiais, o obxectivo é conseguir que fagan un aproveitamento das horas non presenciais contempladas no deseño dos créditos ECTS (EEES) asignados á materia. Con isto, o alumnado desenvolve e asimila os conceptos traballados na materia.

A medida que se van creando os materiais solicitados no proxecto, cada grupo vai subindo os materias creados ao Google Classroom, o que permite o control de actividade por parte do equipo docente. Finalmente, a avaliación establécese por competencias. 


\section{RESULTADOS}

A proposta definida xorde como resposta teórica ao experimentado polos docentes nas aulas da materia de Análise das Operacións Financeiras. A materia impártese no primeiro cuadrimestre. Neste curso 2018/19, realizáronse pequenos cambios no esquema tradicional que se viña aplicando, mais non se aplicaron todos os cambios metodolóxicos aquí suxeridos. Realizáronse varias actividades empregando os grupos cooperativos para traballar o primeiro achegamento aos conceptos básicos da materia. E os resultados son moi positivos. Tratarase, na medida do posible, implementar paseniñamente a proposta suxerida nos cursos vindeiros, avaliando cada curso o novo elemento introducido.

\section{CONCLUSIÓNS}

- As metodoloxías activas permiten a dinamización do papel do alumnado no contexto do EEES.

- 0 papel do docente pasa a ser o dun guía no proceso de ensino-aprendizaxe.

- 0 "contrato de aprendizaxe" é unha ferramenta interesante que inclúe tanto o traballo da responsabilidade como da motivación do alumnado. Constitúe, por tanto, un elemento chave da proposta baseada na aprendizaxe activa e autodirixida.

- A combinación dun proceso propositivo-provocativo e doutro formativo-creativo permite conxugar 0 achegamento inicial á materia co desenvolvemento e asimilación dos conceptos da mesma.

\section{REFERENCIAS}

Cano, R. (2009). Tutoría universitaria y aprendizaje por competencias ¿Cómo lograrlo?. Revista Electrónica Interuniversitaria de Formación del Profesorado, 12 (1), pp. 181-204. Recuperado de: http://www.aufop.com/

Fernández, M. \& De-Llano, F. (2013). El Plan de Acción Tutorial en la Universidad: Seguimiento del PAT de la Facultad de Economía y Empresa de la UDC y su función como plataforma 
educativa integral dentro del EEES. Taller Docente de la XV Reunión de Economía Mundial (REM). La riqueza cambiante en la Economía Mundial, Santander. Recuperado de: https://dialnet.unirioja.es/servlet/articulo? codigo $=4268883$.

Franquet, T., Marín, D., Marqués, M. \& Rivas, E. (2006). El contrato de aprendizaje en la enseñanza universitaria. Actas del $4^{0}$ Congreso Internacional "Docencia Universitaria e Innovación", pp. 1-15. Último acceso via web (06/12/2018): http://campus.usal.es/ ofeees/NUEVAS_METODOLOGIAS/AUTONOMO/Franquet\%20Sugra\%F 1es\%20et\%20al\%20-\%20Contrato\%20de\%20aprendizaje[2].pdf

Gil, C. (2017). Estratexias de Aprendizaxe Cooperativa e uso do Portafolio Dixital en Grupo. Documentación de traballo do Curso "Estratexias de aprendizaxe cooperativa e desenvolvemento do portafolio dixital en grupo" (febreiro 2017), Universidade da Coruña.

Miguel Díaz, M. de (2006). Modalidades de enseñanza centradas en el desarrollo de competencias. Orientaciones para promover el cambio metodológico en el marco del EEES. Oviedo: Ediciones Universidad de Oviedo.

Molina, J., García, A., Pedraz, A. \& Antón, V. (2007). Aprendizaje basado en problemas: una alternativa al método tradicional. Revista de la Red Estatal de Docencia Universitaria 3 (2), pp. 79-85.

Zabalza, M.A. (2011). Metodología docente. Revista de Docencia Universitaria, 9 (3), pp. 7598. Recuperado de: http://red-u.net/redu/files/journals/1/articles/302/public/302-627-1PB.pdf. 